\title{
ATIVIDADE COLINESTERÁSICA NO PLASMA E EM ERITRÓCITOS DE PORTADORES DE MEGACOLO CHAGASICO
}

\author{
Valdemar Hial, Juarez Pimentel de Ulhõa, Vander Figueiredo Reis, Roseli A S Gomes \\ Adriana C Perez
}

\begin{abstract}
A atividade colinesterásica foi medida no plasma e em eritrócitos de 32 individuos. Em 16 pacientes, seguramente portadores de megacolo chagásico, os niveis de colinesterase no plasma $(1.540 \pm 318 \mathrm{UI} / \mathrm{L})$ e nos eritrócitos $(53,2 \pm 9,1 \mathrm{UI} / \mathrm{g} \mathrm{Hb})$ estavam significativamente diminuidos, quando comparados com os niveis enzimáticos no plasma $12.554 \pm$ $826 \mathrm{UI} / \mathrm{L})$ e nos eritrócitos $(63,6 \pm 11 \mathrm{UI} / \mathrm{g} \mathrm{Hb})$ do grupo controle $(n=16)$. Os resultados mostram um paralelismo entre a atividade colinesterásica sistêmica e os achados histopa. tológicos.
\end{abstract}

(Palavras-chaves: Acetilcolinesterase, Pseudocolinesterase, Megacolo, Doença de Chagas)

A acetilcolina é hidrolisada por duas enzimas distintas: acetilcolinesterase (E.C.3.1.1.7) ou colinesterase "verdadeira", encontrada principalmente nos neurônios, nas junções neuromusculares e em eritrócitos, e pseudocolinesterase ou butirilcolinesterase (E.C.3.1.1.8), amplamente distribuida em diversos tecidos, incluindo o plasma sangüíneo e as células de Schwann. Elas são facilmente distingülveis bioquímicamente pois, enquanto a pseudocolinesterase é inibida por sulfato de quinidina, a acetilcolinesterase não apresenta o mesmo comportamento frente àquele inibidor ${ }^{5}$.

Está bem estabelecido que no homem e em animais de laboratório, o Trypanosoma cruzi causa lesões no sistema nervoso autônomo com consecutiva redução numérica dos neurônios, especialmente no coração, esôfago e colo ${ }^{89}$ 1112140 fato é tão proeminente que Koberle $^{8}{ }^{9}$ acredita que os megas de origem chagásica são devidos à desnervação parassimpá- tica. A maioria dos investigadores brasileiros parece estar de acordo com Kuberle e admite que no megaesôfago e megacolo as lesões do plexo de Auerbach constituem a principal alteração anatômica responsável pela modificação da motilidade do órgão e, mais precisamente, dos reflexos peristálticos extrínsecos e intrínsecos.

Tarufi \& Maria ${ }^{13}$ estudando o componente vesicular do plexo de Auerbach no esôfago, admitem que os distúrbios da peristalse observados nos megas são devidos, pelo menos em parte, a distúrbios na biossíntese e liberação de aminas farmacologicamente ativa nas vesículas granulares. Ehrenpreis e Pernov ${ }^{3}$ encontraram alterações quantitativas de substância $P$ no megacolo congênito (doença de Hirschprung). Observaram baixas contrações desse peptídeo no segmento aganglionar $e$ altas concentrações na porção ganglionar. Hial e cols. ${ }^{6}$ realizaram uma análise quantitativa de

\footnotetext{
Trabalho realizado com auxflio financeiro do CNPa no Departamento de Bioquímica e Biofisica e no Departamento de Cirurgia da Faculdade de Medicina do Triângulo Mineiro.
}

\footnotetext{
Endereço para correspondència: Prof. Valdemar Hial, Departamento de Bioquímica e Biofísica, Faculdade de $N$ dicina do Triāngulo Mineiro, 38.100 Uberaba MG, Brasil
}

Recebido para publicação em 18/09/82 
substância $P$ no megaesôfago chagásico. Nos megas e nos esôfagos controles os valores de súbstância $P$ variam de caso para caso e o teste $t$ aplicado às médias, não mostrou diferenças estatísticamente significativas entre mega e controle normal.

Certamente, não poderíamos ignorar o possível papel que devem desempenhar outros bem conhecidos e estabelecidos mediadores químicos, tais como, acetilcolina, catecolaminas, histamina, serotonina, bradicinina e prostaglandinas na doença de Chagas. Em diferentes tipos de inflamações, alguns desses mediadores desempenham funções mais proeminentes, devido à relativa sensibilidade dos tecidos nos quais eles são produzidos. Este é um aspecto interessante a ser analisado nos megas e na doença de Chagas como um todo. Qual ou quais daqueles mediadores seriam mais importantes para explicar as alterações locais e sistêmicas encontradas nos chagásicos? Não podemos ainda deixar de referir ao papel que desempenhariam certas enzimas ou sistemas enzimáticos envolvidos no metabolismo daqueles mediadores químicos, como por exemplo, acetilcolinesterase, monoamino-oxidade, histidina descarboxilase, calicreinas e prostaglandina sintetase.

A determinação da atividade colinesterásica no plasma e em eritrócitos de portadores de megacolo chagásico e o seu envolvimento na fisiopatogênese desta moléstia, constituiu-se no objetivo do presente trabalho.

\section{MATERIAL E MÉTODOS}

O grupo controle constou de 16 indivíduos considerados clinicamente normais e com reações de Machado-Guerreiro e imunofluorescência para $T$. cruzi negativas. O grupo chagásico constou de 16 indivíduos, com reações de Machado-Guerreiro e imunofluorescência para $T$. cruzi positivas e, portadores de megacolo, diagnosticado através de exames clínico e radiológico; teve-se o cuidado de eliminar individuos possuidores de outras entidades patológicas.

$O$ sangue era colhido de individuos em jejum de $12 \mathrm{~h}$ em frasco contendo heparina. A seguir dosava-se a hemoglobina e o sangue total era centrifugado a $3.000 \mathrm{rpm}$ durante 10 minutos, separando-se o plasma e as hemácias que eram lavadas três vezes com solução de cloreto de sódio a $0,85 \%$.

\section{Dosagem da colinesterase}

A determinação da atividade colinesterásica baseou-se no método de Ellman e cols ${ }^{4}$. Os reagentes, com exceção do sulfato de quinidina, foram de procedência Boehringer Mannheim GMBH Diagnostica (Cat. no 15984). A absorbância foi medida com espectrofotômetro Bausch-Lomb, modelo Spectronic 88.

Método para dosagem de colinesterase em eritrócitos

Em $3 \mathrm{ml}$ de tampão fosfato $50 \mathrm{mM}, \mathrm{pH} 7,2$, contendo ácido 5,5'-ditiobis-2-nitrobenzoico $0,25 \mathrm{mM}$, adicionava-se $10 \mu \mathrm{I}$ de sulfato de qui nidina $0,1 \%$ e $5 \mu$ l de concentrado de hemácias previamente lavadas com solução de cloreto de sódio a $0,85 \%$ Após agitar cuidadosamente, adicionava-se $20 \mu \mathrm{I}$ de substrato de acetiltiocolina $5 \mathrm{mM}$, misturava-se com espátula de plástico e media-se a absorbância em $412 \mathrm{~nm}$, a $25^{\circ} \mathrm{C}$, em intervalos de 1 minuto. Realizava-se 4 leituras em 4 intervalos consecutivos.

A atividade da enzima foi calculada de acordo com a equação:

$\mathrm{a}=\Delta \mathrm{A} \times 4,46 \times 10^{3}$ Umoles $/(\mathrm{min} . \mathrm{gHb})$, onde $\Delta \mathrm{A}=$ variação da absorbância e $\mathrm{Hb}=$ hemoglobina. Os resultados foram expressos em $\mathrm{UI} / \mathrm{g} \mathrm{Hb}$.

\section{Método para dosagem da colinesterase no plasma}

Em $3 \mathrm{ml}$ de tampão fosfato $50 \mathrm{mM}, \mathrm{pH} 7,2$, contendo ácido 5,5'-ditiobis-2-nitrobenzoico $0,25 \mathrm{mM}$, adiconava-se $20 \mu \mathrm{I}$ de plasma. A seguir, adicionava-se $100 \mu \mathrm{l}$ do substrato de acetiltiocolina $5 \mathrm{mM}$, misturava-se com espátula e media-se a absorbância em $412 \mathrm{~nm}$, a $25^{\circ} \mathrm{C}$, em intervalos de 1 minuto. Realizava-se leituras em 4 intervalos consecutivos.

A atividade enzimática foi calculada de acordo com a equação:

$a=\Delta A \times 11,47 \times 10^{3}$ umoles $/(\min . L)$, onde $\triangle A$ =variação da absorbância. Os resultados foram expressos em UI/L.

\section{RESULTADOS}

A atividade colinesterásica no plasma e em eritrócitos de indivíduos controle $(n=16)$ e de chagásicos portadores de megacolo $(n=16) \mathrm{en}$ contra-se na Tabela 1. No paciente J.L.O. não nos foi possivel determinar a atividade enzimática nos eritrócitos.

No plasma, a média e o desvio padrão, para o grupo controle e para o grupo de megacolo. foram respectivamente, $2.254 \pm 823 \mathrm{UI} / \mathrm{L}$ e $1.540 \pm 318 \mathrm{UI} / \mathrm{L}(\mathrm{p}<0,001)$. Nos eritrócitos, a 
Hial, Valdemar. Ulhôa, Juarez Pimentel de. Reis, Vander Figueiredo. Gomes, Roseli AS. Perez, Adriana C. Atividade Colinesterásica no Plasma e em Eritrócitos de Portadores de Megacolo Chagásico. Revista da Sociedade Brasileira de Medicina Tropical. 16. 00 a 00, 1983.

média e o desvio padrão, para o grupo controle e para o grupo portador de megacolo, foram respectivamente, $63,6 \pm 11,0 \mathrm{UI} / \mathrm{g} \mathrm{Hb}$ e $53,2 \pm$ $9,1 \mathrm{Ul} / \mathrm{g} \mathrm{Hb}(\mathrm{p}<0,005)$. As diferenças entre as médias dos grupos controle e chagásico, tanto no plasma, como em eritrócitos, foram significativas, embora exista sobreposição de valores para ambos os grupos. Esta sobreposição é, entretanto, menor no plasma do que em eritrócitos.

Tabela 1 - Atividade colinesterática no plasma e em eritrócitos de indivíduos controles normais e de indivíduos portadores de megacolo chagásico.

\begin{tabular}{|c|c|c|c|c|c|}
\hline \multicolumn{3}{|c|}{ Grupo Controle } & \multicolumn{3}{|c|}{ Grupo com Megacolo } \\
\hline \multirow[t]{2}{*}{ Protocolo } & \multirow{2}{*}{$\frac{\text { Plasma }}{\text { UI/L ( })}$} & \multirow{2}{*}{$\frac{\text { Eritrócito }}{\text { UI/g Hb }\left(^{*}\right)}$} & \multirow[t]{2}{*}{ Protocolo } & \multirow{2}{*}{$\frac{\text { Plasma }}{\text { UI/L }}$} & Eritrócito \\
\hline & & & & & $\mathrm{UI} / \mathrm{g}$ \\
\hline W.P.G.P & 3.728 & 57,2 & E.P.S & 1.927 & 49,2 \\
\hline J.J.S. & 2.179 & 77,2 & A.J.S & 1.675 & 52,5 \\
\hline D.A.J. & 1.778 & 83,4 & F.C. & 1.136 & 51,3 \\
\hline G.A.V. & 2.065 & 69,7 & G.M.O. & 1.709 & 54,4 \\
\hline J.R.F. & 2.248 & 79,6 & A.C. & 1.169 & 49,8 \\
\hline B.A.D. & 4.530 & 66,9 & L.R.S. & 1.583 & 55,0 \\
\hline S.J.N. & 1.835 & 56,9 & B.S.S. & 1.743 & 45,8 \\
\hline N.G.P. & 2.409 & 67,2 & A.D. & 1.720 & 41,8 \\
\hline O.C.N. & 2.936 & 62,7 & F.M.B. & 1.720 & 38,2 \\
\hline G.P.O. & 2.065 & 52,1 & A.G.C. & 1.353 & 45,8 \\
\hline G.I. & 2.466 & 51,1 & E.A.A. & 1.526 & 67,6 \\
\hline N.S.D. & 1.755 & 50,5 & J.L.O. & 1.606 & -- \\
\hline J.A.S. & 2.902 & 57,6 & G.M.R. & 1.376 & 60,5 \\
\hline J.M.D. & 1.548 & 69,6 & A.P.O. & 918 & 59,1 \\
\hline J.A.N. & 2.868 & 46,5 & J.D.P. & 2.179 & 55,3 \\
\hline M.J.F. & 3.556 & 69,4 & H.J.S. & 1.308 & 72,4 \\
\hline $\bar{x}$ & 2.554 & 63,6 & $\bar{x}$ & 1.540 & 53,2 \\
\hline$s$ & 826 & 11,0 & $\hat{s}$ & 318 & 9,1 \\
\hline
\end{tabular}

(*) UI/L = unidade internacional por litro

(-) $\mathrm{Ul} / \mathrm{g} \mathrm{Hb}=$ unidade internacional por grama de hemoglobina

\section{DISCUSSÃO}

Boston e cols. ${ }^{2}$ encontraram aumento significativo da atividade colinesterásica tanto no soro como em eritrócitos de pacientes com doença de Hirschsprung, quando comparada a de controles normais. Segundo estes autores, a colinesterase presente localmente no segmento afetado do intestino seria a fonte dos elevados níveis sangürneos observados na doenço de Hirschsprung. Por outro lado, admitem haver uma queda relativa da completa hidrólise catalítica de acetilcolina na porção aganglionar do intestino e, assim sendo, a elevada atividade colinesterásica no soro e nos eritrócitos representaria um mecanismo compensador para sua degradação sistêmica. De fato, elevados niveis de colinesterase no segmento aganglionar foram reportados por outros pesquisadores ${ }^{1} 10$.

Alterações quantitativas de acetilcolina foram também detectadas por Ikawa e cols. ${ }^{7}$ em portadores de megacolo congênito. Estes autores encontraram niveis elevados do mediador no segmento aganglionar, quando comparados com os níveis do colo ganglionar. Este é um aspecto interessante com relação ao comportamento de medidadores químicos pois, na doença de Hirschsprung os níveis de substância $P$ estão diminuindo na porção aganglionar quando compara. dos com o segmento ganglionar e, a acetilcolina comporta-se de modo inverso. 
Hial, Valdemar. Ulhôa, Juarez Pimentel de. Reis, Vander Figueiredo. Gomes, Roseli AS. Perez, Adriana C. Atividade Colinesterásica no Plasma e em Eritrócitos de Portadores de Megacolo Chagásico. Revista da Sociedade Brasileira de Medicina Tropical. 16. 00 a 00, 1983.

Os nossos estudos mostram uma diminuição significativa da atividade colinesterásica, tanto no plasma (pseudocolinesterase) como em eritrócitos (acetilcolinesterase) de portadores de megacolo chagásico, comparados com controles normais.

Tafuri ${ }^{15}$, através de microscopia eletrônica, verificou que tanto os neurônios como as células de Schwann estavam comprometidos no megacolo de origem chagásica. Os nossos dados mostram um paralelismo entre as alterações histológicas e a atividade colinesterásica pois, tanto a acetilcolinesterase de origem neuronal, como a pseudocolinesterase originária das células de Schwann, estão diminuídas.

A hipótese que Boston e cols. ${ }^{2}$ levantaram para explicar o aumento sistêmico da atividade colinesterásica, não nos convence totalmente. Acreditamos que o aumento da atividade pseudocolinesterásica seja, em parte, devido à hiper- plasia das células de Schwann que ocorre no segmento aganglionar do megacolo congênito. Quanto ao aumento da atividade acetilcolinesterásica nos eritrócitos, cabe-nos detalhar um pouco mais. É sabido que a acetilcolinesterase localiza-se na superfície externa da membrana da hemácia ${ }^{5}$. É provável, portanto, que sua fonte também sejam os neurônios e que a membrana da hemácia possua receptores para essa enzima. Isto é admissível, uma vez que lipídios contendo colina localizam-se na camada mais externa da membrana do eritrócito ${ }^{17}$.

Os nossos estudos, comparados aos de Boston e cols. ${ }^{2}$, permitem estabelecer, a nível molecular (atividade colinesterásica), diferenças entre megacolo chagásico e megacolo congênito, a exemplo do que já haviamos demonstrado para a substância $P^{6}, 16$.

\section{SUMMARY}

Cholinesterase activity was measured in the plasma and erythrocytes from 32 individuals. The 16 patients, in whon the diagnosis of Chagasic megacolon confirmed, had a significantly lower concentration of the enzyme both in plasma $(1.540 \pm 318 \mathrm{YI} / \mathrm{L})$ and ery. throcytes $(53.2 \pm 9.1 \mathrm{UI} / \mathrm{g} \mathrm{Hb})$ when compared with the 16 controls in whom, the plasma and erythrocyte cholinesterase leve/s were, respectively, $2.554 \pm 823$ and $63.6 \pm 11 \mathrm{UI} / \mathrm{g}$ $\mathrm{Hb}$. The results show a correlation between the systemic cholinesterase activity and the histopathological findings.

(Key-words: Acety/cholinesterase, Pseudocholinesterase, Megacolon, Chagas'Disease)

\section{REFERÉNCIAS BIBLIOGRÁFICAS}

1. Boston VE, Dale G, Riley KWA. Diagnosis of Hirschsprung's disease by quantitative biochemical assay of acetylcholinesterase in rectal tissue. Lancet 2:951-953, 1975

2. Boston VE, Cywes S, Davies MRO. Serum and erythrocyte acetylcholinesterase activity in Hirschsprung's disease. Journal of Pediatric Sugery 13:407-410, 1978

3. Ehrenpreis T, Pernow B. On the occurrence of substance $P$ in the rectosigmoid in Hirschsprung's disease. Acta Physiologica Scandinavica $27: 380-388,1952$
4. Ellman GL, Courtney KD, Andres JRV, Featherstone RM. A new and rapid colorimetric determination of acetilcholinesterase activity. Biochemical Pharmacology 7:8895,1961

5. Hers F, Kaplan E. A Review: Human erytrocyte acetylcholinesterase. Pediatric Research 7:204-214, 1973

6. Hial V, Diniz CR, Pittella JEH, Tafuri WL Quantitative study of $P$ substance in the megaesophagus and megacolon of human Trypanosoma cruzi infections. Journal of Tropical Medicine and Hygiene 76:175-179, 1973 
7. Ikawa H, Yokoyama J, Morikawa Y, Hayashi $A$, Katsumata $K$. A quantitative stu dy of acetylcholine in Hirschsprung's disease. Journal of Pediatric Surgery 15:48-52, 1980

8. Kóberle F. Die Chagaskrankheit: eine Erkrankung der Neurovegetativen Peripherie. Wiener Klinische Wochenschrift 68:333339,1956

9. K'oberle F. Die Chagaskrankheit. Ihre $\mathrm{Pa}$ thogenese und ihre Bedeutung als Volkseuche. Zeitschrift Für Tropenmedizin und Parasitologie 10:236-266, 1959

10. Meier-Ruge W, Lutterbeck PM, Herzog B, Morger R, Moser R, Schárli A. Acetylcholinesterase activity in suction biopsies of the rectum in the diagnosis of Hirschsprung's disease. Journal of Pediatric Surgery 7:11. 17,1972

11. Tafuri WL. Microscopia eletrônica do miocárdio na fase aguda da tripanossomíase cruzi experimental. Revista do Instituto de Medicina Tropical de São Paulo 11:151. 164, 1969

12. Tafuri WL. Microscopia eletrônica do colo do camundongo na fase aguda da tripanossomíase cruzi experimental. Revista da Associação Médica de Minas Gerais 20:209220, 1969
13. Tafuri WL, Maria TA. Sobre o comportamento do componente vesicular neurossecretor no megaesôfago da tripanossomíase cruzi humana. Revista do Instituto de Me. dicina Tropical de São Paulo 12:298-309, 1970

14. Tafuri WL, Maria TA, Lopes ER. Lesões do plexo mientérico do esôfago, do jejuno e do colo de chagásicos crônicos. Estudos ao microscópio eletrônico. Revista do Instituto de Medicina Tropical de São Paulo 13:76. 91, 1971

15. Tafuri WL Alterações ultra-estruturais dos componentes muscular, intersticial e nervoso do coração e intestinos, na doenca de Chagas experimental e humana. Tese para Professor Titular, Universidade Federal de Minas Gerais, Belo Horizonte, 1974

16. Tafuri WL, Maria TA, Pittella JEH, Bogliolo $L$, Hial V, Diniz CR. An electron microscopy study of the Auerbach's plexus and determination of substance $P$ of the colon in Hirschsprung's disease. Virchows Archives. (A) Pathology. Anatomy and Histology $362: 41-50,1974$

17. White A, Handler P, Smith EL, Hill RL, Lehman LR. Principles of biochemistry. Mcgraw-Hill, Kogakusha Tokyo, p 992, 1978 